they do not merely give the cards away, but themselves collect them and forward to me, as my experience has so fully demonstrated that not 5 per cent. of the recipients will take the trouble of returning them directly to me.

A collection of IoOO family measurements would be of immense value for testing various problems in heredity, and, if it be formed, I shall be only too glad that it should be ultimately deposited where it would be available for all future students of heredity.

It is, perhaps, needless to remark that the measurements required are of normal and not pathological characteristics, and no name except that of the recorder (in case of there being need of reference) is required.

All communications should be addressed to me at University College, London.

University College, London, April ro.

\section{The Retinal Circulation.}

TrE phenomenon of the retinal circulation, referred to in Mr. James W. Barrett's letter in NATURE of April 2, was, I believe, first described by Dr. Robert Waring Darwin in 1786 . He writes:- "By being accustomed to observe such small sensations in the eye, it is easy to see the circulation of the blood in this organ." . . . "It is sometimes necessary to rub the eyes with a certain degree of force after they are closed, and to hold the breath rather longer than is agreeable, which by accumulating more blood in the eye, facilitates the experiment." $\mathrm{He}$ further states that it depends on the state of health, is most distinct when the eye is fatigued, and is best seen by looking at the sky, shading the eyes with the hand.

I have myself seen it often when a boy under much the same conditions as your correspondent, viz. lying on my back looking up at the blue sky after severe exercise.

But about fifteen years ago I discovered a method of observ. ing it far more perfectly. While calibrating a somewhat powerful spectroscope by measuring the Fraunhofer lines with a very narrow slit and direct sunlight, I noticed that when the region between $G$ and $H$ occupied the field of view, the retinal circulation showed so plainly as to inconvenience me. On slightly altering the focus, so as to get rid of the lines, I could see not only the corpuscles, but the walls of the capillaries themselves with great distinctness, especially when the eye began to be fatigued. With a sufficiently narrow slit the corpuscles were visible against the other parts of the spectrum, even the red, but they appeared as mere specks, and the outlines of the vessels could no longer be discerned. Judging from this that violet light was more important than a narrow slit, I tried last year the effect of various coloured media. Of these the most successful was ammonio-sulphate of copper. A six-ounce flask, filled with a solution of this substance, held close to the eye about a yard from an arc-lamp, enabled me to see the retinal circulation and some of the vessels, but not nearly so distinctly as with the violet light of the pure spectrum.

Oxford.

\section{JUPITER AND HIS PERIOD OF ROTATION.}

$A$ QUESTION which has recently been attracting considerable interest with regard to the greatest of our planets, Jupiter, relates to the determination of the time of rotation deduced from observations of markings on the visible surface of this planet's disc. The difficulty to be contended with here is that the appearance of the markings on the disc is always changing, and further great changes, even in short intervals of time, are noticeable. The chief characteristic features of the disc are the dark belts situated on each side of the equator, resembling to some extent the two belts of trade winds on the earth, which lie on either side of the belt of equatorial calms and rains. More minute scrutiny reveals to us other belts which are sometimes seen in considerable numbers, while their individual structure is by no means simple. These details are for the most part only temporary, and so quickly do changes take place, that the surface of the planet seldom, if ever, appears the same two nights together. Often spots are observed among these belts, which are generally of a more distinct nature than the usual markings ; these are for the most part dark, but in some cases they are bright, round, and small, resembling the satellites as they travel across the primary's disc.

The extreme lack of constancy in the positions and forms of all the surface-markings has long ago taught us to cast aside the idea that we are looking at the surface of a rigid body. What we really see is the dense vapour and cloudlike formations between us and the real surface, encircling the whole planet from pole to pole, and always in a state of turmoil. This and other reasons have given us sufficient evidence to form some idea of the temperature of the planet itself, and it is now thought that the internal temperature is considerable, and probably sufficient to render the planet capable of shining to a small extent by its own light.

In consequence of the proper motion of several spots observed on Jupiter's surface and the primitive state of his atmosphere, the planet is said to resemble the sun to some extent. On account of these many points of similarity, Zöllner was led to believe that perhaps a similar law of rotation might here be in vogue which had been proved to hold good in the case of the sun by observations of spots on his surface. Lohse also, some time afterwards, after a minute discussion of all the available evidence, came to a similar conclusion, namely, that Jupiter in the region of his equator rotated quicker than in regions some distance from it.

Now this question is by no means so easy to settle as may seem at first sight. In the first place, in the cases of both the sun and this planet, the spots that are generally visible are confined to two belts north and south of the equator, while the equator and the poles are, for the most part, devoid of all such markings.

In the case of the sun, however, one need not necessarily be restricted to spot observation to determine the time of rotation near the poles, for we possess a very simple means of solving this problem by the application of Doppler's principle. The sun's limb on the east and west sides will be rotating towards and away from the observer, and an examination with the spectroscope of these regions will show us, by measuring the displacement of the lines in the spectrum from their normal positions, the velocities in the two directions. Curiously enough, both Crew and Dunér made investigations on this principle, and the results obtained were by no means the same, but, on the contrary, apparently antagonistic. The former, who observed the photosphere, found that for all latitudes the time of rotation was the same, while the latter, who examined the spots spectroscopically, obtained a decrease in the velocity as their distance from the equator increased. To explain these apparently contradictory results, Brester suggested that it seemed probable that Dunér observed the spectral lines of gases situated inside the photosphere, while Crew's observations were restricted in all probability to gases in those atmospheric layers which lie above the photosphere.

As yet no such observations near the poles of Jupiter have been attempted, although, as will be seen further on, this application of Doppler's principle has been employed for the region near the equator. Fortunately, however, in the year 1892 (October 10) a short dusky streak, oblong in shape, was observed by Stanley Williams near the north limb, extending nearly to north latitude $85^{\circ}$. Other similar streaks have been subsequently noticed, and frequent determinations of the times of mid-transit have been made. By good fortune the observers at the Lick Observatory had secured at the same time some good photographs of the planet, the surface-markings of which, on the negative, were sufficiently distinct for measurement.

A comparison of the times of rotation deduced from both the visual and photographic records seemed to give very satisfactory results, the mean periods differing only

No. I 38 I, VOL. 53 ] 
by two seconds. The mean result for the surface material of Jupiter between latitudes $40^{\circ}$ to $85^{\circ}$ north gave $9 \mathrm{~h} .55 \mathrm{~m} .38 .9 \mathrm{~s}$. $\pm 1 \cdot 20$ s., this being the length of a sidereal rotation expressed in mean solar time. Observations of some dark, well-defined spots in I89I gave as a value for the period of rotation $9 \mathrm{~h} .55 \mathrm{~m} .38 \cdot 5 \mathrm{~s}$., while Denning found $(1894-5)$ the value $9 \mathrm{~h} .55 \mathrm{~m}$. $39^{\circ}$ os., still closer to that given above.

It will be noticed that up to the present the observations of Stanley Williams do not corroborate a reduction in the rate of rotation in higher latitudes, as would be expected from Lohse's discussion. The observations of the two may, however, be harmonised to some extent if, as before, one supposes that they observed markings at different levels in the atmosphere of the planet. If this were so, then very probably Stanley Williams generally watched those markings in the higher regions, whilc the spots observed by Lohse were situated at a far deeper level, and in which perhaps were strong currents.

A spectroscopic investigation of great interest is that due to Dr. Belopolsky, who undertook the determination of the velocity of a point in the equatorial region of Jupiter. The method of procedure was as follows. He assumed that the equatorial region of this planet made one rotation every $9 \mathrm{~h}$. $5 \mathrm{om}$.; knowing the angular diameter of the disc from measures made with the micrometer, he then calculated the velocity of a point on the equator, the resulting velocities being $\mathrm{I} 2$ and $\mathrm{I} 3 \mathrm{kilo-}$ metres per second, according to the special value of the diameter used. The second part of the work consisted in observing the east and west limbs of the planet spectroscopically, using the principle of Doppler to find out the displacement of the lines due to the velocities in the line of sight. The value he obtained was I I 4 kilometres per second, a number smaller than that which would apparently be expected. The great difference between the observed and computed velocity may be due to errors of observation, but its magnitude calls for another explanation. Belopolsky himself prefers to account for this difference by regarding it as a result of refraction, an assumption which is quite permissible, as Schmidt has shown in his theory of the sun.

Perhaps the best idea of the drift of the Jovian surface can be gathered from a summary of the determinations of the length of the period made from surface-markings at different Jovian latitudes. This table we owe to Mr. Stanley Williams, and it appeared in a previous number of NATURE (vol. liii. p. 376). It will be noticed that the nine zones represent practically nine distinct currents in the planet's atmosphere, their boundaries being described as sharply defined. These currents completely encircle the planet, and have an east and west direction; very little indications of motion towards the poles having been noticed.

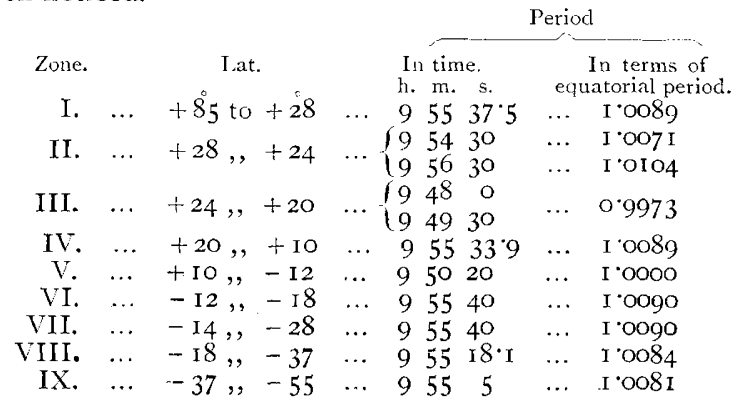

Curiously enough, the zone numbered VII., which represents the red-spot zone, has not an equivalent in the northern hemisphere, that numbered III. having a much quicker drift.

Apropos of this red spot zone, we may mention that

Mr. Stanley Williams expresses the opinion that the NO. I 38 I, VOL. 53 ] mysterious red spot acts in the same way as, and has some analogy to, an island in a river (Knowledge, April). The spot lies between the south equatorial belt and the south temperate belt, and as the white material between these two belts drifts past the red spot with a velocity of sixteen miles per hour, it is obliged to force a passage round the spot. Most of this white material passes to the north side of the spot, making a depression in the south equatorial belt; but some of it finds a way through a very narrow channel on the south side. There is less resistance to the passage of the material on the north side of the spot, probably for the reason that the surface is most plastic in the equatorial regions. As the channels on the north and south sides of the red spot are together narrower than the main channel, there is a heaping up of white material on the following side of the spot and in the channels, and this seems to possibly explain the bright annulus which is frequently seen encircling the red spot. The union of the two currents produces a commotion on the preceding side of the spot, giving rise to the hazy patch which is usually visible in that position. As a working hypothesis, the idea seems likely to be of use in suggesting observations, but it is admittedly difficult to conceive how such an effective obstacle as the red spot can drift about in the way it has done.

The latest observations regarding Jupiter's surface thus show us that the whole disc of vapour that we see is in a state of slow circulation in currents more or less parallel to the equator. The rifts that appear to traverse the disc in the north and south direction may be the effects of a slow circulation in this direction.

The east and west currents do not then necessarily increase their rate of rotation the nearer the equator is approached; but there may be zones of quicker rotation. followed by zones of slower rotation before the equator be reached. It will thus be seen that a very accurate value of the period of rotation of Jupiter is difficult to determine, since the several drifts are in relative motion one with another.

W. J. S. L.

\section{THE LIFE OF JOSEPH WOLF.'}

$\mathrm{I} \mathrm{T}$ seems now to be rather in fashion to write lives of persons still in existence. In some cases, such as the present, there is little to be said against this practice ; in others, it may be open to very serious objections. But when the biography of a living person is given to us by an intimate personal acquaintance, we have, at any rate, one advantage: it may be assumed that the narrative has been more or less supervised by the person to whom it relates, and that the facts and incidents stated are generally correct. Such, we know, is not always the case with biographies of departed heroes.

Joseph Wolf, well known to all zoologists as the "Prince of Animal Painters," and one whom savants and artists alike agree to class as "absolutely unrivalled" in his special department, was the son of a German farmer, or what was formerly called in the south of England a "yeoman," farming his own land at the little village of Möerz, between Trèves and Coblentz. Born in I820, Wolf was sent to the village school at Metternich, where his observant habits and "superior skill in drawing maps" told favourably with the master. But to his fellow-scholars a boy who "refrained from bird-nesting on principle," and would fight any of them in defence of a nest of young birds, was somewhat of a puzzle. Here, however, Wolf had many opportunities, both during his school-days and in the course of the initiation into farmlife which followed, of studying nature. A fine wild country was around him, where beasts and birds were abundant, and he soon taught himself to observe them, 1 "The Life of Joseph Wolf, Animal Painter." By A. H. Palmer.
Illustrated. Pp. xviii +328 . (London: Longmans, r895.) 